\title{
Circadian Profiling of the Arabidopsis Proteome Using 2D-DIGE
}

\author{
Mani K. Choudhary ${ }^{1}$, Yuko Nomura ${ }^{2}$, Hua Shi ${ }^{3}$, Hirofumi Nakagami ${ }^{2}$ and \\ David E. Somers ${ }^{1,3 *}$
}

1 Division of Integrative Biosciences and Biotechnology, Pohang University of Science and Technology, Pohang, South Korea, ${ }^{2}$ Plant Proteomics Research Unit, RIKEN Center for Sustainable Resource Science, Yokohama, Japan, ${ }^{3}$ Department of Molecular Genetics, Ohio State University, Columbus, OH, USA

OPEN ACCESS

Edited by:

Rob McClung,

Dartmouth College, USA

Reviewed by:

Eva Farre,

Michigan State University, USA Joshua Gendron,

Yale University, USA He Huang,

Donald Danforth Plant Science Center,

USA

*Correspondence:

David E. Somers

somers.24@osu.edu

Specialty section:

This article was submitted to

Plant Cell Biology,

a section of the journal

Frontiers in Plant Science

Received: 16 April 2016

Accepted: 27 June 2016

Published: 12 July 2016

Citation:

Choudhary MK, Nomura Y, Shi H, Nakagami $H$ and Somers DE (2016) Circadian Profiling of the Arabidopsis

Proteome Using 2D-DIGE.

Front. Plant Sci. 7:1007. doi: 10.3389/fpls.2016.01007
Clock-generated biological rhythms provide an adaptive advantage to an organism, resulting in increased fitness and survival. To better elucidate the plant response to the circadian system, we surveyed protein oscillations in Arabidopsis seedlings under constant light. Using large-scale two-dimensional difference in gel electrophoresis (2D-DIGE) the abundance of more than 1000 proteins spots was reproducibly resolved quantified and profiled across a circadian time series. A comparison between phenol-extracted samples and RuBisCO-depleted extracts identified 71 and 40 rhythmically-expressed proteins, respectively, and between 30 and 40\% of these derive from non-rhythmic transcripts. These included proteins influencing transcriptional regulation, translation, metabolism, photosynthesis, protein chaperones, and stress-mediated responses. The phasing of maximum expression for the cyclic proteins was similar for both datasets, with a nearly even distribution of peak phases across the time series. STRING clustering analysis identified two interaction networks with a notable number of oscillating proteins: plastid-based and cytosolic chaperones and 10 proteins involved in photosynthesis. The oscillation of the ABA receptor, PYR1/RCAR11, with peak expression near dusk adds to a growing body of evidence that intimately ties ABA signaling to the circadian system. Taken together, this study provides new insights into the importance of post-transcriptional circadian control of plant physiology and metabolism.

Keywords: circadian clock, proteomics, abscisic acid (ABA) signaling, chaperones, 2D-DIGE

\section{INTRODUCTION}

The circadian clock controls many aspects of plant metabolism and development and is most closely associated with the transcriptional regulation of these processes. Numerous genetic studies in plants have examined the performance of photosynthesis, growth, and survival under stresses in clock mutant backgrounds, and changes in the gene expression of key elements of these processes are typically found (Green et al., 2002; Dodd et al., 2005; Mizuno and Yamashino, 2008; Fukushima et al., 2009; Legnaioli et al., 2009; Graf et al., 2010; Greenham and McClung, 2015). Transcriptome analyses have implicated the circadian clock in the rhythmic control of mRNA levels (Harmer et al., 2001; Covington et al., 2008; Hazen et al., 2009; Filichkin et al., 2011; Nose and Watanabe, 2014) and genome-wide studies have shown the wide-ranging roles of clock components in the control of gene expression (Gendron et al., 2012; Huang et al., 2012; Nakamichi et al., 2012; Hsu et al., 2013; Liu et al., 2013; Nagel et al., 2015). These findings include clock control of the plant circadian oscillator itself as well as many output genes involved in metabolism, physiology, and development. 
Fewer studies, both in plants and animals, have examined the circadian control of post-transcriptional processes such as mRNA and protein turnover, and post-translational modifications such as phosphorylation, ubiquitinylation, and sumoylation (Kim et al., 2003; Cardone et al., 2005; Reddy et al., 2006; Deery et al., 2009; Mehra et al., 2009; Mauvoisin et al., 2014a,b; Seo and Mas, 2014; van Wijk et al., 2014; Choudhary et al., 2015; Nolte and Staiger, 2015). Additionally, the presumption that protein oscillations will follow from transcript cycling is not always borne out. About $20-50 \%$ of circadian cycling proteins in the liver lack accompanying mRNA oscillations (Reddy et al., 2006; Mauvoisin et al., 2014b; Robles et al., 2014) and in the suprachiasmatic nucleus only between 11 and $38 \%$ of the rhythmic proteins show significantly rhythmic mRNA (Deery et al., 2009). Studies like these indicate that transcriptome kinetics do not necessarily predict proteomic profiles.

Therefore, analysis of the proteome is essential to understand how cellular processes respond to, and are controlled by, the circadian clock. Since the development of proteomic techniques in the last few decades rhythmic proteins have been detected using high throughput methods including two-dimensional in gel electrophoresis (2-DE), mass spectrometry (MS), and MALDI-TOF. Proteomic approaches have been used to identify clock-associated proteins and circadian oscillations in proteins in dinoflagellates (Akimoto et al., 2004), Chlamydomonas reinhardtii (Wagner et al., 2004; Wagner and Mittag, 2009), and Ostreococcus taurii (Le et al., 2011). Analysis of the clock-regulated proteome of higher plants has been limited to one study in rice (Hwang et al., 2011) and the Arabidopsis phosphoproteome (Choudhary et al., 2015).

To further study the changes in Arabidopsis circadian proteome and to deepen our understanding of the extent of clock control of protein oscillations, we use two-dimensional difference in gel electrophoresis (2D-DIGE) to identify polypeptides in Arabidopsis seedlings that oscillate in abundance under constant light. Through the inclusion of an internal standard (IS) for normalization, this technique allows the analysis of up to three pools of protein samples simultaneously on a single $2 \mathrm{D}$ gel, thereby minimizing gel-to-gel variability (Alban et al., 2003). We utilized two different methods of sample preparation. A comprehensive total protein extract (phenol extraction) was compared to the protein profile obtained from D-ribulose bisphosphate carboxylase/oxygenase (RuBisCO)depleted samples. This immuno-affinity approach was applied in an effort to enhance the detection of low abundance proteins that might be masked by the very high levels of RuBisCO present in green tissue (Sehrawat et al., 2013; Aryal et al., 2015).

Together more than 100 oscillating proteins were identified that are involved in transcriptional regulation, translation, metabolism, photosynthesis, protein chaperones, and stress-mediated responses. We were able to highlight previously undescribed protein oscillations in chaperones involved in chloroplast import and photosynthesis and make new connections between the circadian clock and ABA signaling.

\section{MATERIALS AND METHODS}

\section{Plant Materials and Growth Conditions}

Arabidopsis Columbia ecotype seeds were surface sterilized and cold-treated for 2 days to synchronize germination. Seeds were plated on filter paper in petri dish containing growth medium Murashige and Skoog basal salt mixture, 3.0\% sucrose, and 1.0\% agar ( $\mathrm{pH}$ 5.7). Seedlings were grown under $12 \mathrm{~h}$ white fluorescent light $\left(120 \mu \mathrm{mol} \mathrm{m} \mathrm{m}^{-2} \mathrm{~s}^{-1}\right), 12 \mathrm{~h}$ light/12 h dark cycle for 10 days at $22^{\circ} \mathrm{C}$ and then maintained under constant light for 24 $\mathrm{h}$ before harvesting. The tissues were harvested at the indicated time points (LL25, LL29, LL 33, LL37, LL41, and LL45) and frozen immediately (Table S1).

\section{Extraction of Total Proteins for 2D-Dige}

Total proteins were extracted with the phenol-methanol method (Hurkman and Tanaka, 1986) with modifications. Approximately $0.1 \mathrm{~g}$ of tissue were ground into fine powder in liquid nitrogen and mixed with three volumes of SDS extraction buffer (100 $\mathrm{mM}$ Tris- $\mathrm{HCl}, \mathrm{pH} 8.0,2 \%$ SDS, $1 \% \beta$-mercaptoethanol, $5 \mathrm{mM}$ EGTA, $10 \mathrm{mM}$ EDTA), vortexed vigorously, and centrifuged at $20,000 \times \mathrm{g}$ for $20 \mathrm{~min}$. The supernatant was mixed with an equal volume of ice-cold phenol (Tris-buffered, $\mathrm{pH}$ 7.5-7.9) and centrifuged at $20,000 \times \mathrm{g}$ for $15 \mathrm{~min}$ at $4^{\circ} \mathrm{C}$ to separate phenol and aqueous phases. The upper aqueous phase was removed leaving the interface intact, and the phenol phase was extracted twice with $50 \mathrm{mM}$ Tris- $\mathrm{HCl}, \mathrm{pH}$ 8.0. It was then mixed with five volumes of cold $0.1 \mathrm{M}$ ammonium acetate in methanol and held at $-20^{\circ} \mathrm{C}$ overnight to precipitate proteins. After centrifugation at $20,000 \times \mathrm{g}$ for $20 \mathrm{~min}$, the protein pellet was washed three times with $1 \mathrm{ml}$ of cold $0.1 \mathrm{M}$ ammonium acetate in methanol and once with ethanol and then resuspended in buffer $(30 \mathrm{mM}$ Tris-Cl, $7 \mathrm{M}$ urea, $2 \mathrm{M}$ thiourea, 4\% CHAPS $\mathrm{pH}$ 8.5). After centrifugation, the supernatant was transferred to a new tube, and the solubilized protein sample concentration was quantified with 2-D quant kit (GE Healthcare) using BSA as a standard.

\section{RuBisCO Depletion by Immunoaffinity Purification}

Seedlings were ground into fine powder in liquid nitrogen and homogenized in $(1: 3, \mathrm{w} / \mathrm{v})$ buffer $(10 \mathrm{mM}$ Tris $\mathrm{pH} 7.5,150$ $\mathrm{mM} \mathrm{NaCl}, 0.5 \% \mathrm{NP}-40$, protease inhibitor). The homogenate was centrifuged at $12,000 \mathrm{rpm}$ for $20 \mathrm{~min}$ at $4^{\circ} \mathrm{C}$. The protein concentration was determined with the Bio-Rad protein assay using BSA as a standard. The supernatant was subjected to immunoaffinity purification (Seppro IgY RuBisCO Spin Column kit, Sigma-Aldrich) following the manufacturer's instructions. Briefly, the column was pre-washed thrice with $500 \mu \mathrm{L}$ Tris buffered saline (TBS, $1 \mathrm{mM}$ Tris- $\mathrm{HCl}, 150 \mathrm{mM} \mathrm{NaCl}$, and $\mathrm{pH}$ 7.4). Immuno-capture of $\mathrm{RuBisCO}$ was performed by incubating the supernatant (100 $\mu \mathrm{g}$ protein) with the matrix for $15 \mathrm{~min}$ at $25^{\circ} \mathrm{C}$ with gentle shaking. After $15 \mathrm{~min}$, the flow through was collected by centrifugation at $2000 \mathrm{rpm}$ for $30 \mathrm{~s}$. Unbound protein were removed by washing with TBS. Elution was done with the stripping buffer (100 mM glycine- $\mathrm{HCl}, \mathrm{pH} 2.5)$ and the fractions were immediately neutralized with $1 \mathrm{M}$ Tris- $\mathrm{HCl}, \mathrm{pH}$ 8.0. 


\section{Protein CyDye Labeling}

Proteins were labeled with DIGE-specific Cy2, Cy3, or Cy5 according to the manufacturer's instructions (GE Healthcare) with modifications. Briefly, after adjusting $\mathrm{pH}$ to 8.5 using $\mathrm{NaOH}$ $(100 \mathrm{mM}), 50 \mu \mathrm{g}$ of proteins were mixed with $400 \mathrm{pmol}$ of CyDye and incubated on ice in the dark for at least $10 \mathrm{~min}$. The reaction was stopped by addition of $1.0 \mu \mathrm{l}$ of $10 \mathrm{mM}$ lysine and incubated on ice for $10 \mathrm{~min}$. Each sample was covalently labeled with a fluorophore, either Cy3 or Cy5. A mixture of equal amounts of protein from every sample in the experiment was labeled with Cy2 and used as internal standard.

\section{Two-Dimensional Gel Electrophoresis}

For analytical 2D-DIGE analysis $50 \mu \mathrm{g}$ each of Cy3-, Cy5-, and Cy2-labeled protein samples were mixed together (total $150 \mu \mathrm{g}$ of protein). The DIGE sample buffer [7 $\mathrm{M}$ urea, $2 \mathrm{M}$ thiourea, $4 \%$ CHAPS, 20 mM DTT, and 0.5\% IPG buffer (GE Healthcare)] was added to bring the volume to $450 \mu \mathrm{l}$, and the samples were then applied to 24-cm Immobiline Drystrips (GE Healthcare) and rehydrated overnight. IEF was carried out on an Ettan IPGphor II (GE Healthcare) at $20^{\circ} \mathrm{C}$ with a maximum of $50 \mu \mathrm{A} /$ strip and the following setting: 500 and $1000 \mathrm{~V}$ each for $1 \mathrm{~h}$, a gradient increase to $8000 \mathrm{~V}$ over $3 \mathrm{~h}$, and remaining at $8000 \mathrm{~V}$ until an accumulated voltage of reaching the desired total V-h (72,000 for pH 4-7 IPG strips). After IEF, IPG strips were equilibrated in equilibration buffer [6 M urea, 30\% (w/v) glycerol, 2\% SDS, $50 \mathrm{mM}$ Tris- $\mathrm{HCl}$, $\mathrm{pH}$ 8.0] first with $0.5 \%$ DTT and then with $2 \%$ iodoacetamide each for $15 \mathrm{~min}$. The equilibrated strips were then transferred to $12.5 \%$ SDS-PAGE gels for the second dimension electrophoresis using the Ettan Dalt-six (GE Healthcare/Amersham Biosciences) vertical unit. SDS-PAGE was run overnight: the first step at 80 $\mathrm{V}$, for $1 \mathrm{~h}$, the second step at $120 \mathrm{~V}$, until the bromophenol blue dye front reached the bottom of gel. Four biological trials were performed at each time point.

\section{D-DIGE Image Analysis}

Gels were processed using a Typhoon 9410 scanner (GE Healthcare/Amersham Biosciences) according to the manufacturer's recommendations for DIGE image analysis. The DIGE images were analyzed using Progenesis Same Spots software v4.0 (Nonlinear Dynamics, Durham, NC). The scanned images were matched, and artifacts, damaged areas, and spots on the gels or on the scanner bed were removed. Analysis using Progenesis software included spot detection, background subtraction, normalization, and matching. Normalization was done using an internal standard (IS) sample. The internal pooled standard allows the comparison of more than two proteomes without the need to perform pair-wise analysis of all possible combinations of data points. After automatic spot detection, manual editing was performed to ensure that spots were correctly matched between different gels and were not contaminated with artifacts, such as streaks or dust. Spots were manually revised with edition tools for correct detection. Gel groups were established according to the experimental design and spot normalized volume was used to select statistically significant (fold change, ANOVA) differentiated spots between time points. The setting was fixed in each experiment so that fewer than three spots presence on at least three of the four replicates, including presence on the reverse labeled one would be considered as a false positive.

Preparative 2D gels loaded with $1 \mathrm{mg}$ of protein were used for spot picking. These gels were loaded with equal amounts of pooled samples from all 24 samples (six time points from four biological trials). After electrophoresis the gel was silver stained, scanned with a transmission-light densitometer (Image Scanner; GE Healthcare), and aligned with the DIGE reference image with Progenesis SameSpots to outline the spots of interest selected in the previous analysis. The spots were excised manually from three preparative gels for each extraction method.

\section{In-Gel Tryptic Digestion, Mass Spectrometry, and Database Searching}

In-gel digestions were performed as described previously (Shevchenko et al., 2006). Digested peptides in the gel pieces were recovered by adding 5\% formic acid/acetonitrile, desalted using StageTips with C18 disk membranes (EMPORE, 3M; Rappsilber et al., 2003), dried in a vacuum evaporator, and dissolved in $9 \mu \mathrm{L}$ of $5 \%$ acetonitrile containing $0.1 \%$ trifluoroacetic acid. An LTQ-Orbitrap XL (Thermo Fisher Scientific) coupled with an EASY-nLC 1000 (Thermo Fisher Scientific) was used for nano-LC-MS/MS analyses. A self-pulled needle (150 mm length $\times 100-\mu \mathrm{m}$ i.d., $6-\mu \mathrm{m}$ opening) packed with ReproSil C18 resin (3 $\mu \mathrm{m}$; Dr. Maisch $\mathrm{GmbH}$ ) was used as an analytical column with "stone-arch" frit (Ishihama et al., 2002). A spray voltage of $2400 \mathrm{~V}$ was applied. The injection volume was $6 \mu \mathrm{L}$, and the flow rate was $500 \mathrm{~nL} \mathrm{~min}{ }^{-1}$. The mobile phase consisted of $0.5 \%$ acetic acid (A) and $0.5 \%$ acetic acid and $80 \%$ acetonitrile (B). A two-step linear gradient of $0-40 \%$ B in $30 \mathrm{~min}, 40-100 \%$ $\mathrm{B}$ in $5 \mathrm{~min}$, and $100 \% \mathrm{~B}$ for $10 \mathrm{~min}$ was employed. The MS scan range was $\mathrm{m} / \mathrm{z} 300-1400$. The top 10 precursor ions were selected in the MS scan by Orbitrap at 100,000 resolution and for subsequent MS/MS scans by ion trap in the automated gain control mode, where automated gain control values of $5.00 \mathrm{e}+05$ and $1.00 \mathrm{e}+04$ were set for full MS and MS/MS, respectively. The normalized collision-induced dissociation was set to 35.0. A lock mass function was used for the LTQ-Orbitrap $\mathrm{XL}$ to obtain constant mass accuracy during gradient analysis (Olsen et al., 2005). Selected sequenced ions were dynamically excluded for $60 \mathrm{~s}$ after sequencing. Mass Navigator version 1.3 (Mitsui Knowledge Industry, Tokyo, Japan) with default parameters for LTQ-Orbitrap XL was used to create peak lists on the basis of the recorded fragmentation spectra. The $\mathrm{m} / \mathrm{z}$-values of the isotope peaks were converted to the corresponding monoisotopic peaks when the isotope peaks were selected as the precursor ions. To improve the quality of the MS/MS spectra, Mass Navigator discarded all peaks of $<10$ absolute intensity and with $<0.1 \%$ of the most intense peak in MS/MS spectra (Ravichandran et al., 2009). Peptides and proteins were identified by means of automated database searching using Mascot version 2.3.02 (Matrix Science) in The Arabidopsis Information Resource database (TAIR10_pep_20101214, ftp://ftp.arabidopsis.org/home/tair/Sequences/blast_datasets/ TAIR10_blastsets/) with a precursor mass tolerance of $3 \mathrm{ppm}$, 
a fragment ion mass tolerance of $0.8 \mathrm{Da}$, and strict trypsin specificity (Olsen et al., 2004), allowing for up to two missed cleavages. Carbamidomethylation of Cys was set as a fixed modification, and oxidation of Met and phosphorylation of Ser, Thr, and Tyr were allowed as variable modifications. Scaffold (version Scaffold_4.5.3, Proteome Software Inc., Portland, OR) was used to validate MS/MS based peptide and protein identifications. Peptide identifications were accepted if they could be established at $\mathbf{9 5 . 0 \%}$ probability by the Peptide Prophet algorithm (Keller et al., 2002). Protein identifications were accepted if they could be established at $>99.9 \%$ probability and contained at least two identified peptides. Protein probabilities were assigned by the Protein Prophet algorithm (Nesvizhskii et al., 2003). Proteins that contained similar peptides and could not be differentiated based on MS/MS analysis alone were grouped to satisfy the principles of parsimony. Contaminants were removed manually. The mass spectrometry proteomics data have been deposited to the ProteomeXchange Consortium via the PRIDE partner repository with the dataset identifier PXD004276 (Vizcaíno et al., 2016).

\section{Immunoblotting}

Growth conditions and harvest of Arabidopsis seedlings were as described previously (Choudhary et al., 2015). Total protein extraction was performed according to Fujiwara et al. (2008). Protein extracts were size-fractionated by $12 \%$ SDS-PAGE. Immunoblotting was performed using polyclonal RuBisCO activase antibody (aA-18, sc-15864, Santa Cruz Biotechnology) with 1:3000 dilution. RCA is known to be phosphorylated and has two detectable isoforms in Arabidopsis, 43 and $47 \mathrm{kDa}$ (Yin et al., 2010). Hence, all detectable bands were used for quantitation. Histone H3 antibody (ab1791, Abcam) was used for loading control with 1:2000 dilution. Image J software was used for quantification of protein signal intensity.

\section{GO, STRING, and SOTA Analysis}

For Gene Ontology (GO) enrichment information for differentially expressed significant proteins data sets, the three GO vocabularies, biological processes, cellular component, and molecular function were searched using the GO Slim Classification for plants developed at TAIR (https://www.arabidopsis.org/tools/bulk/go/index.jsp). The AGI accession numbers for Arabidopsis were uploaded and ontology of GO cellular component, biological process, and molecular function was chosen with other settings as default.

A functional network of circadian modulated proteins was predicted using STRING version 10.0 (Szklarczyk et al., 2015; available at www.string-db.org). Functional protein-association networks were visualized with high confidence (0.7), with Arabidopsis thaliana set as the organism.

Self-organizing tree algorithm (SOTA) clustering was used to obtain the co-expression pattern of differentially expressed significant proteins (Herrero et al., 2001). Clustering was performed on log-transformed fold induction expression values across six time points using Multi Experiment Viewer (MEV) software (The Institute for Genomic Research). The Pearson correlation distance was set at 10 cycles and a maximum cell diversity of 0.9 (Romijn et al., 2005).

\section{RNA Extraction and Quantitative RT-PCR}

Total RNA was extracted with RNAzol reagents (Sigma) according to the manufacturer's instructions from Col-0 seedlings grown on MS media. After digestion with DNase I (Invitrogen), $2 \mu \mathrm{g}$ of total RNA was used to synthesize cDNA by using oligo-dT and SuperScriptIII reverse transcriptase (Invitrogen) following the manufacturer's instructions. The PYR1 gene-specific primers were PYR1qFP: TCCTGCTCCGTCGAA CAAAACTTC and PYR1qRP: CGCCTCCGATGATACTGA ATCCG. The UBQ primers were UBQ qFP: TGCGCTGCCAGA TAATACACTATT and UBQ qRP: TGCTGCCCAACATCA GGTT. qRT-PCR was performed using iQ SYBR Green Supermix (Bio-Rad) and Bio-Rad CFX96 real-time PCR detection system.

\section{RESULTS AND DISCUSSION \\ 2D-DIGE Reveals Circadian Control over Protein Abundance Patterns}

To gain insight into the circadian regulation of protein expression patterns, we analyzed the proteome of Arabidopsis seedlings after entrainment in $12 \mathrm{~h}$ light and $12 \mathrm{~h}$ dark cycles followed by free run under constant white light for $24 \mathrm{~h}$. Samples were subsequently collected at $4 \mathrm{~h}$ intervals starting at LL25. Quantitative proteomics analysis was performed using twodimensional difference in gel electrophoresis (2D-DIGE). To obtain optimal separation of Arabidopsis proteins, we first used a phenol-methanol extraction method (Hurkman and Tanaka, 1986). In a second approach, RuBisCO-depleted samples were tested in an effort to enhance the detection of low abundance proteins that might be masked the very high levels of RuBisCO present in green tissue (Sehrawat et al., 2013; Aryal et al., 2015).

In both approaches four biological replicates were obtained for each time point (12 gels for each extraction method; Table $\mathrm{S} 1$ ). We first analyzed protein samples prepared in parallel from the same tissue samples on 1-D SDS-PAGE gels (Figure S1) and then separated the extracts on high resolution $24 \mathrm{~cm} 2 \mathrm{D}$ gels using the CyDye system (Table S1). The phenol-methanol and RuBisCO-depletion methods consistently yielded highly resolution gels with typically $\sim 1350$ protein spots resolved in each gel (Figure 1, Figure S2). Gel image analysis and protein spots were quantified using Progenesis same spot software and spots that reproducibly changed in abundance between two samples within the time series with $p<0.05(n=4)$ were selected for further examination (77 for the phenol-extracted samples and 59 for the RuBisCO-depleted samples; summaries of peptides matching each protein are in Table S2). A substantial set of changes are apparent by the colored overlay of the fluorescence images. Spots of interest were picked manually from post-electrophoretically silver stained preparative gels and in-gel trypsin-digested. Protein identities were analyzed by LC-MS/MS (Figures 1A,B indicated by arrows). MASCOT software (ver. 2.3.02) was used to simultaneously identify proteins.

From the first set of ANOVA-selected differentially-expressed protein spots, visual inspection narrowed further analysis to 71 


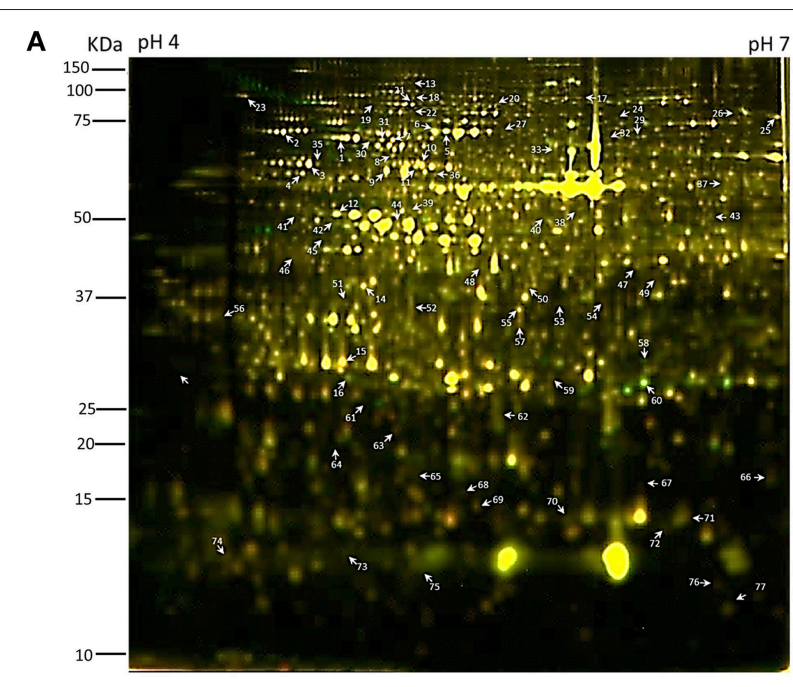

B

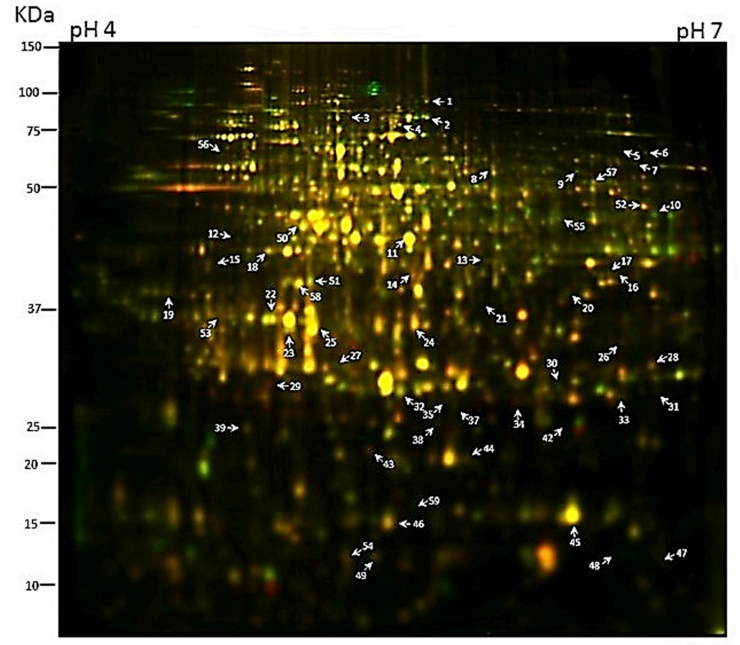

FIGURE 1 | Two-dimensional difference gel electrophoresis (2-D DIGE) analysis of circadian regulated proteins. (A) Total protein isolated through a phenol extraction or (B) RuBisCO-depletion method were compared across the six time points by 2-D DIGE using $24 \mathrm{~cm} \mathrm{pH} \mathrm{4-7} \mathrm{(left} \mathrm{to} \mathrm{right)} \mathrm{IPG} \mathrm{strips}$ and $12.5 \%$ sodium dodecyl sulfate-polyacrylamide gel electrophoresis (SDS-PAGE) gels. Protein spots of interest are numbered. Panel (A) is an overlap image of gel no. 1 (Table S1) with the LL25 sample labeled with Cy3 and the LL37 sample labeled with Cy5. Panel (B) is an overlap image of gel no. 4 (Table S1) with the LL29 sample labeled with Cy3 and the LL33 sample labeled with Cy5.

spots from the phenol-extracted samples, and 40 spots from the RuBisCO-depleted samples which showed circadian-like waveforms (Tables S3, S4). Some peptides were identified in multiple spots, which was likely caused by post-translational modifications that shift the mobility in $2 \mathrm{D}$ gels. Typically many proteins of different families were identified within a single gel spot. Spot identity was then assigned to the protein having the highest percentage of total MS spectra coming from that spot (top hit; Tables S5, S6; see Section Methods and Conclusion).

The co-expression profile of the oscillating peptides was represented by a heat map (Figure S3) using the MEV software (The Institute of Genomic Research, TIGR; Saeed et al., 2003).
The phase distributions of the cyclic proteins were similar for both datasets, with a similar number of peak phases across the time series (Figures 2A,C). These results differ from a recent circadian phosphoproteome analysis where peak phosphopeptide abundance occurred just after subjective dawn and subjective dusk (Choudhary et al., 2015). mRNA phasing patterns in Arabidopsis were more evenly distributed across day and night, though there was still a slight bias toward near dusk and near dawn (Harmer et al., 2000). Rhythmic proteins from both extraction methods mostly correlated with rhythmic transcripts (56 and 69\%; phenol-extracted and RuBisCOdepleted, respectively; Figures 2B,D). Thus, between ca. 30 and $40 \%$ of rhythmic proteins derive from non-rhythmic transcripts, and these were not associated with a particular circadian phase (Figures 2B,D). These results are similar to an Arabidopsis phosphoproteomic study which reported that more than half of the cycling phosphopeptides came from genes with arrhythmic transcripts (Choudhary et al., 2015). Similar findings were reported from mouse liver studies, where $20-50 \%$ of the rhythmic proteins did not exhibit corresponding rhythmic transcripts (Reddy et al., 2006; Mauvoisin et al., 2014b; Robles et al., 2014). Taken together, these results emphasize the importance of circadian control over post-transcriptional and post-translational processes that lead to the net result of rhythmic patterns of protein abundance.

\section{Immunoaffinity Removal of RuBisCO}

RuBisCO-depletion spin columns $\left(\right.$ Seppro ${ }^{\circledR}$ IgY affinity purification; SIGMA) effectively removed the large and small subunit of RuBisCO (Figure 3; compare boxed areas in Figures $\mathrm{S} 2 \mathrm{~A}, \mathrm{~B})$. One indication of the effectiveness of RuBisCO depletion is the many fewer number of RuBisCO peptides identified in the depleted samples (10) compared to the phenol-extracted samples (45; Table S7). Surprisingly, only four proteins were found common to both data sets as the top hit in the respective spots: cold, circadian rhythm RNA-binding 2 (CCR2/ATGRP7; spot P69 and S59), phosphoglycerate kinase 1 (PGK1; spot P42 and S50), RuBisCO activase (RCA; spot P06, P12 and spot $\mathrm{S} 11$ ), and ribulose-1,5-bisphosphate carboxylase/oxygenase (RuBisCO) small subunit (RBCS; spot P73 and S49; Tables S3, S4; Figure 4). CCR2/ATGRP7 is an RNA-binding protein that is part of a molecular slave oscillator associated with the Arabidopsis circadian system (Schmal et al., 2013). Both extraction methods showed the same late-day peak phase of CCR2 protein (Heintzen et al., 1997), similar to the transcript, but the amplitude of oscillation was more robust using the RuBisCO-depletion extraction method (Figures 4A-C).

Peak RCA protein abundance was early-day phased for both methods and slightly phase-delayed relative to peak RCA mRNA abundance (Figures 4D-F). We validated these results by immunoblot using whole seedling extracts grown under the same entrainment and free-running conditions. Peak RCA levels occurred at the same phase and with similar amplitude as that obtained from the two 2D-DIGE data sets (Figure 5). Both approaches resolved oscillations with a two-fold or less range in abundance, indicating a high degree of sensitivity and reproducibility using $2 \mathrm{D}-\mathrm{DIGE} / \mathrm{MS}$. 
A

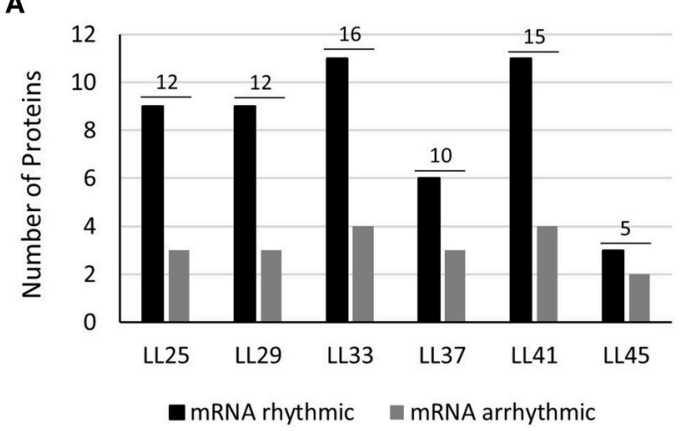

B

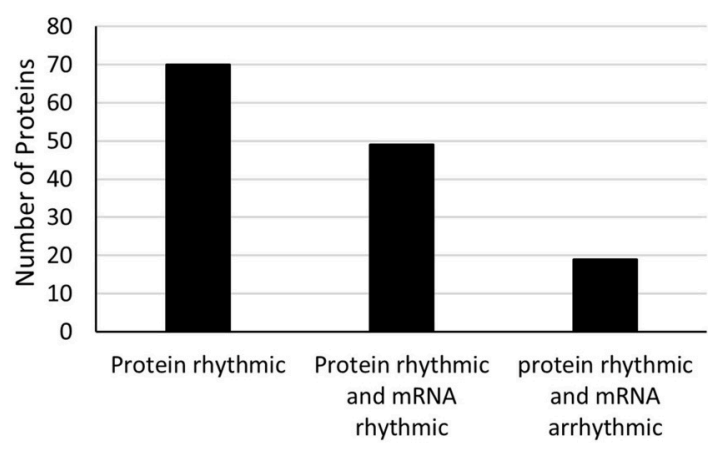

C

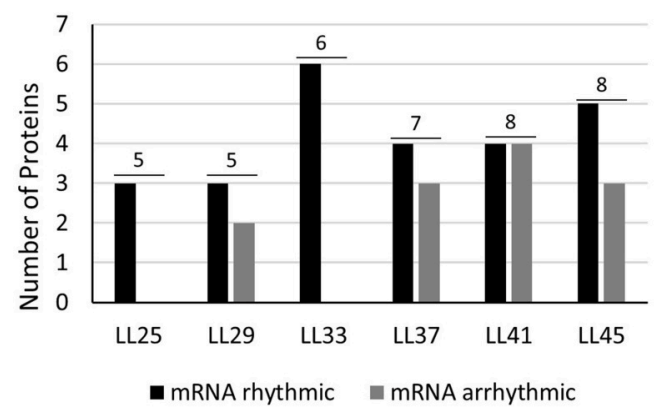

D

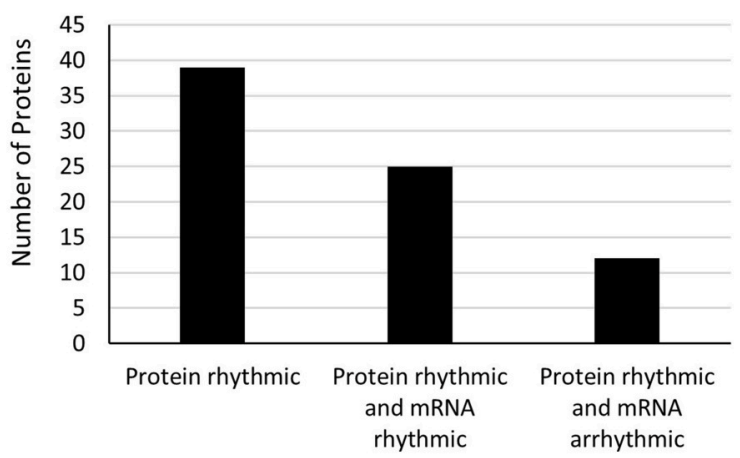

FIGURE 2 | Protein distribution by circadian phase and mRNA rhythmicity. Number of rhythmic proteins (Phenol extracted) are shown as the number above the two bars for each phase of peak occurrence $\mathbf{( A )}$ and relative to whether the respective mRNA is also rhythmic (B). Peak phasing of rhythmic proteins are further shown according to whether the respective mRNA is rhythmic (dark bar) or whether the respective mRNA is arrhythmic (gray bar). (C,D) Results for same categories obtained from RuBisCO-depleted protein extracts. Discrepancies between the total number of proteins and the sum of the two bars for each phase is due to mRNA data missing from DIURNAL.

PGK1 is an essential enzyme that catalyzes the reversible ATPdependent phosphorylation of 3-phosphoglycerate (3-PGA) in the chloroplast, as well participating in the glycolytic pathway in the cytosol (Morisse et al., 2014). PGK1 protein oscillations from the RuBisCO-depleted samples were phased very similar to the transcript (Figures 4G-I).

Two to three isoforms of the RuBisCO small subunit (RBCS3B/RBCS2B and RBCS1A) showed different phases of peak oscillation (Figures 4J-L). RBCS3B/RBCS2B (spot S49; Table S4) maximally accumulated during subjective day, dropping to lowest levels in the early evening. RBCS1A (spot P73; Table S3) was anti-phasic to $2 \mathrm{~B} / 3 \mathrm{~B}$, rising to maximal levels at subjective dusk. The significance of these two forms of RuBisCO peaking at different times is unclear. Interestingly, RBCS1A expression is highest in plants grown at low temperatures, with levels dropping in plants grown at higher temperatures. However, $\mathrm{RBCS} 3 \mathrm{~B} / \mathrm{RBCS} 2 \mathrm{~B}$ expression rises strongly with increasing growth temperatures (Yoon et al., 2001). Further work on the phasing and oscillation amplitude of these RBCS proteins in plants grown at different temperatures could be very informative.

\section{GO Analysis}

For further characterization we performed GO analysis using TAIR Slim GO for cellular component, molecular function and biological process. The cellular component representation is extremely similar for both the protein extraction procedures, but there is slightly less representation of chloroplast and plastid protein in the RuBisCO-depleted extracts (48 vs. 50\%), possibly reflecting the removal of RuBisCO (Figure 6A). Within the molecular function category, proteins involved in enzymatic activity and protein and nucleotide binding are the major players in both data sets. At the biological process level proteins related to stress response and protein metabolism are the major contributors (Figure 6). Thus, the two types of extractions displayed a high degree of similarity in the relative contribution of three different GO vocabularies examined.

\section{String Analysis}

The STRING database allows accumulated protein-protein interaction data to be assembled and viewed as interaction networks (Szklarczyk et al., 2015). Using STRING we identified and focus on groupings of rhythmic proteins associated with photosynthesis (the phenol-extracted and RuBisCO-depleted data sets) and chaperones (phenol-extracted data set; Figure 7).

\section{Photosynthesis}

Taken together the two proteome data sets identified 10 proteins or protein families associated with photosynthesis that oscillate with a circadian period (Figures 7A,B). As noted above, 
members of the RBCS protein family, RCA and PGK1 were common to both approaches. Two proteins involved in the regulation of photosystem II appear in more than one spot and with different peak phases (PSBO2; S22, S23, S25, and

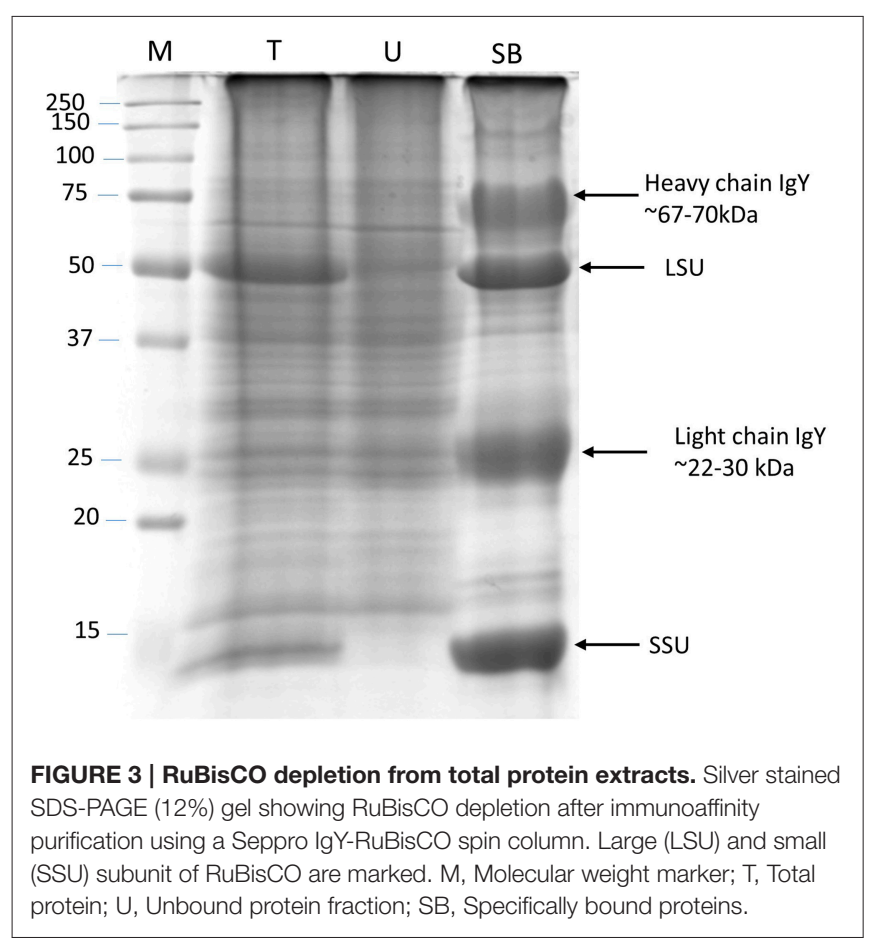

PSBP-1; P16, P22; Tables S3, S4). Both undergo post-translational modifications (PhosPhAt 4.0; Zulawski et al., 2013), which may account for the same polypeptides migrating into different gel spot positions. The different peak phasings among the spots are intriguing and suggest a change in the extent of the modification within each protein (likely phosphorylation; Zulawski et al., 2013) over circadian time (Tables S3, S4).

Two proteins with nearly identical profiles, PETC/PGR1 (spot S42; Table S4) and ATPC1 (spot S13; Table S4), show maximum accumulation at LL $45,3 \mathrm{~h}$ before subjective dawn. PETC/PGR1 is a component of the cytochrome b6-f complex and confers resistance to photo-oxidative damage (Maiwald et al., 2003). ATP synthase gamma chain 1 (ATPC) is an essential element of the light-dependent regulation of chloroplast ATP synthase activity (Wu et al., 2007). It is intriguing that under constant light the maximum accumulation of both proteins occurs well before the anticipated time of dawn. It is possible that under normal dark/light conditions the onset of light acutely induces an additional boost in accumulation of both proteins, which would be additive to the high baseline established by circadian system in the dark. This would enhance, during the daylight hours, the levels of both proteins which are so necessary to photosynthesis.

\section{Chaperones}

Both proteome data sets identified circadian oscillations in chaperone levels. The plastid-localized chaperonin 60 alpha2 and beta3 (Cpn60a2 and Cpn60ß3) were identified in the phenolextracted data set (Table S3). Cpn60 is found in the stroma and is instrumental in the maturation of RuBisCO large subunit

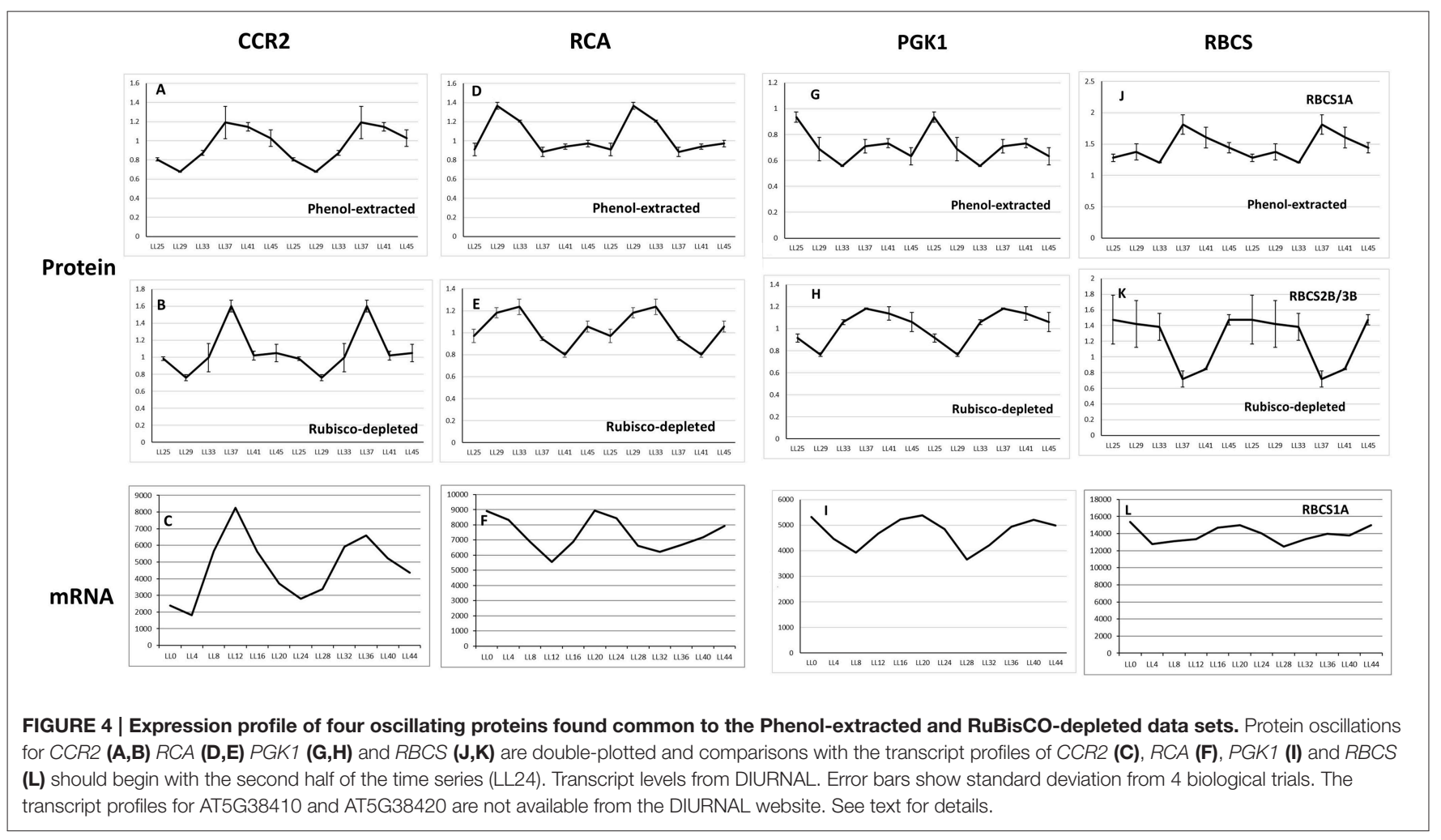




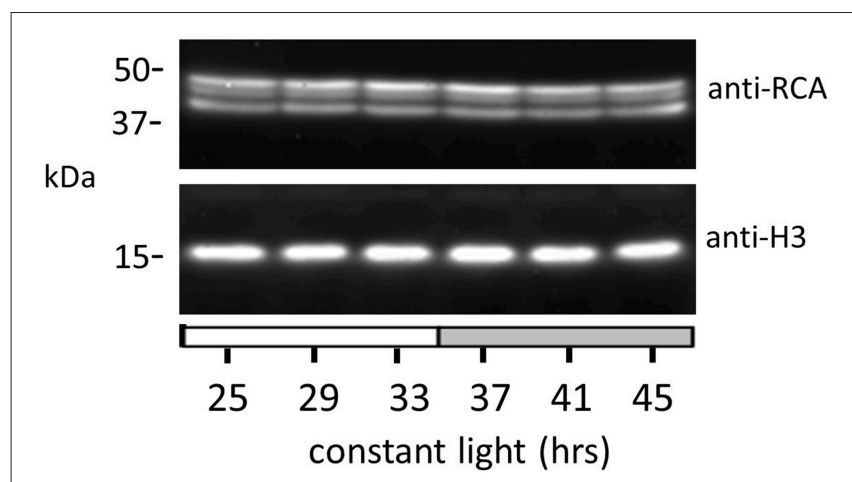

RCA/H3

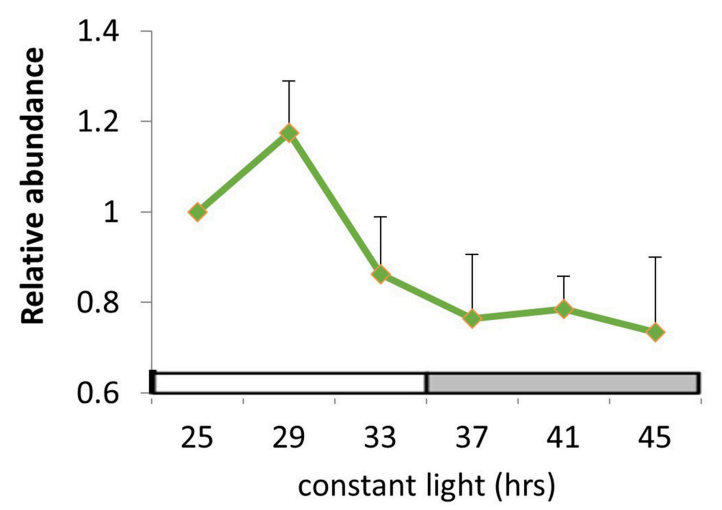

FIGURE 5 | RuBisCO activase protein oscillation in constant light. Immunodetection of RuBisCO activase (RCA) protein abundance. Ten-day-old Arabidopsis Col-0 seedlings grown under LD cycles were released to continuous light and harvested at the indicated time. White and gray bars indicate subjective day and night. Protein level was quantitated relative to histone $\mathrm{H} 3$ and normalized to the level of LL25. Error bars indicate s.e.m. from two biological replicates.

( $\mathrm{RbcL}$ ), RuBisCO activase (RCA), and other enzymes associated with photosynthesis (Trösch et al., 2015). The two most robust instances of Cpn60 22 and Cpn60ß3 cycling (P03 and P10; Table S3) are maximally phased at mid to late in the day phase. This is very similar to the phasing of the stroma-localized cpHSC70-1 (P02; Table S3). cpHSC70s are essential to chloroplast development and are key to the import of plastid stromal proteins (Latijnhouwers et al., 2010; Su and Li, 2010; Flores-Pérez and Jarvis, 2013).

ClpC/Hsp93-V was identified in the RuBisCO-depleted data set (S01, S02; Table S4). This chaperone is also involved in plastid protein import, particularly with the TOC/TIC (translocon at the outer/inner chloroplast envelope membrane) complex (Flores-Pérez and Jarvis, 2013). Both isolates were phased with highest presence during the early and midday. Taken together, the similar phasing of maximal protein expression of these three plastid-associated chaperones (Cpn60, cpHSC70, and $\mathrm{ClpC} / \mathrm{Hsp} 93-\mathrm{V}$ ) indicate the importance for strong circadian coordination of plastid protein import and maturation.
Additionally, the cytosolic co-chaperone Hop2 (HSP70 and HSP90 organizing protein) was rhythmically expressed with a morning peak phased slightly earlier than the plastid-associated chaperones (P29, P32; Table S3). Hop can bind to HSP90 and HSP70 simultaneously and acts to facilitate the transfer of nascent client proteins through the intermediate steps that lead to the fully mature client (Zhang et al., 2003; Baindur-Hudson et al., 2015). Interestingly, the Hop co-chaperone has been found in a large complex in association with HSP90 and various chloroplast preproteins (Fellerer et al., 2011). This finding, together with the oscillations in Hop2 levels (Table S3) suggests that maturation of chloroplast-bound proteins, prior to plastid entry, is also under circadian clock control.

HSP70 is well-established as an early-interacting partner in HSP70/HSP90-dependent protein maturation in a wide range of processes in plants and animals (Sung and Guy, 2003; Jung et al., 2013; Radons, 2016). HSP70 was recovered from four different spots in the phenol-extracted data set (P01, P07, P30, and P31; Table S3) which correspond to two cytosolic forms, HSP701/HSC70-1 and HSP70-4 (Lin et al., 2001). Both forms showed early to mid-day peaks in protein oscillations that matches well with peak Hop2 expression (Table S3). The phasing coincidence of these key players in protein maturation adds further support to the notion of circadian regulation in the formation/activity of a HSP70-Hop2-HSP90 complex that processes chloroplast preproteins.

We previously reported robust oscillations in the phosphorylation state of HSP70-1/HSC70-1 (Choudhary et al., 2015). Comparison of HSP70-1/HSC70-1 protein oscillation with its phospho-oscillation indicates a slightly earlier peak in protein levels (LL 33; Table S3) compared to the phosphorylation peak (LL 37). This may indicate that much of the oscillation in HSP70-1/HSC70-1 phosphorylation follows from circadian-driven changes in its protein levels.

There are a number of ways the nuclear-based circadian system exerts control over the chloroplast (Atkins and Dodd, 2014). The clock-regulated nuclear-encoded sigma factor SIG5 can confer oscillations on certain chloroplast-encoded transcripts, demonstrating one level of nuclear control over chloroplast function (Noordally et al., 2013). Direct circadian regulation of tetrapyrolle biosynthesis gene expression and chlorophyll-binding protein gene expression also contribute to chloroplast assembly and function (Millar and Kay, 1991; Matsumoto et al., 2004). Our above results linking clock control of chaperone-mediated protein maturation now reveal an additional level of circadian control to chloroplast assembly and photosynthesis activity.

\section{Abscisic Acid (ABA) Signaling}

Of special note is the distinct circadian oscillation in the abundance of the ABA receptor (PYR1/RCAC11, S37; Table S4; Figure S4). The peak levels occur just after subjective dusk (LL 41) and does not track mRNA levels. DIURNAL (Mockler et al., 2007) reports no apparent mRNA oscillation for the first $24 \mathrm{~h}$ in constant light (Table S4), but a there is a weak oscillation with peak transcript level near LL28-29 (Table S4; Figure S4), anti-phase with the protein peak. This finding is striking in the 

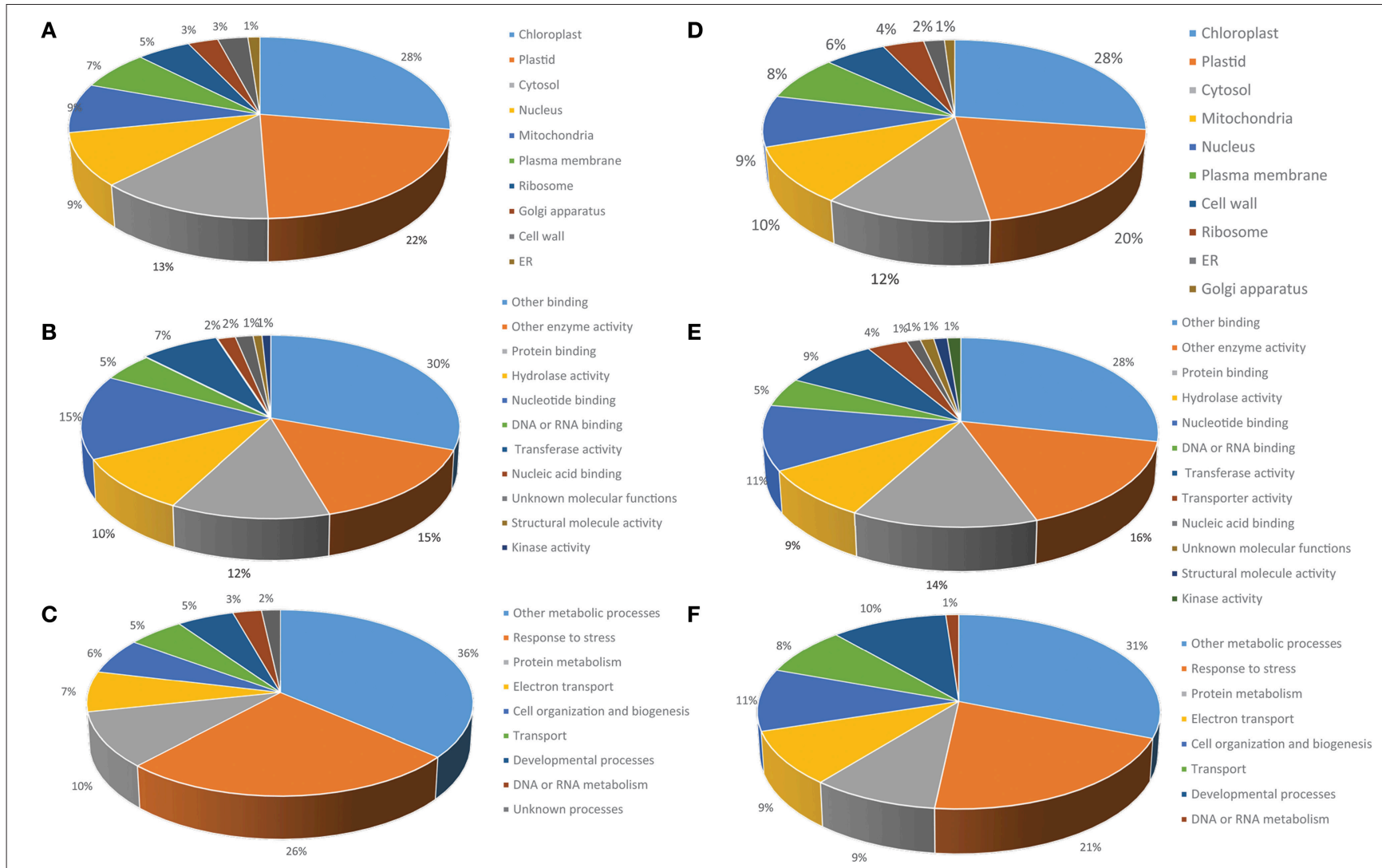

FIGURE 6 | Functional classification of the phenol-extracted circadian-regulated proteins by Go analysis. Percentage GO terms were displayed for three GO vocabularies: (A) Cellular component, (B) Biological process, and (C) Molecular function. (D-F) Results for same categories obtained from RuBisCO-depleted protein extracts.

context of other known levels of clock control over the ABA system.

The ABA signaling pathway begins with three type of components, the ABA receptor (PYR/RCAC proteins), protein phosphatase 2C (PP2C), and sucrose nonfermenting-1 (SNF1)related protein kinase 2 (SnRK2; Yoshida et al., 2015). The downstream signaling initiated by PYR/RCAC binding of ABA strongly relies on the phosphorylation of numerous substrates by SnRK2s at many stages of plant development (Yoshida et al., 2015). A previous phosphoproteomic study identified subjective dusk/early evening (LL37-45) peak phosphorylation of two SnRK2 proteins (SNRK 2.2 and SNRK 2.3), the ABA-regulated transcription factor $\mathrm{AREB} 1 / \mathrm{ABF} 2$ and $\mathrm{ABA}$-responsive gene COR78/RD29a (Choudhary et al., 2015). An ABA/PYR1/PP2C complex activates SnRK2; hence the similar circadian phasing of the receptor and kinase components will accentuate systemic responsiveness to $\mathrm{ABA}$ levels in a late-day phase-dependent way. As well, ABA levels tend to peak in the late afternoon/early evening under light/dark cycles, further heightening ABA signaling potential at this time (Nováková et al., 2005; Lee et al., 2006; Fukushima et al., 2009). Circadian regulation of the transcript abundance of numerous ABA signaling components (e.g., SnRK2.6, ABI1, ABF3, RCAR1, and others Seung et al., 2012) that are similarly dusk/early evening phased highlights the importance of $\mathrm{ABA}$ responsiveness late in the day.

Further, there is a complex interaction between the core circadian system and ABA-responsive factors. TOC1 binds to the promoter of the ABA-related gene ABAR/CHLH/GUN5, repressing its expression and conferring a circadian pattern to $A B A R$ transcript accumulation. Reciprocally, TOC1 expression increases in response to $\mathrm{ABA}$, which requires the presence of $A B A R$ (Legnaioli et al., 2009; Pokhilko et al., 2013). The TOC1-related protein, PRR7, is similarly required for correct phasing of ABA-mediated gene expression (Liu et al., 2013). Additionally, the clock-regulated ABA-inducible R2R3-type MYB transcription factor, MYB96, binds to the TOC1 promoter affecting clock-dependent gating of ABA responses (Lee et al., 2016). The addition of a circadian oscillation in ABA-receptor (PYR1) levels now adds further complexity to the regulation of these downstream interrelationships.

\section{CONCLUSIONS}

Through 2D-DIGE, coupled with mass spectrometry, we surveyed the Arabidopsis seedling proteome for circadianregulated proteins using two different protein extraction techniques. We supplemented a standard phenol-extraction 


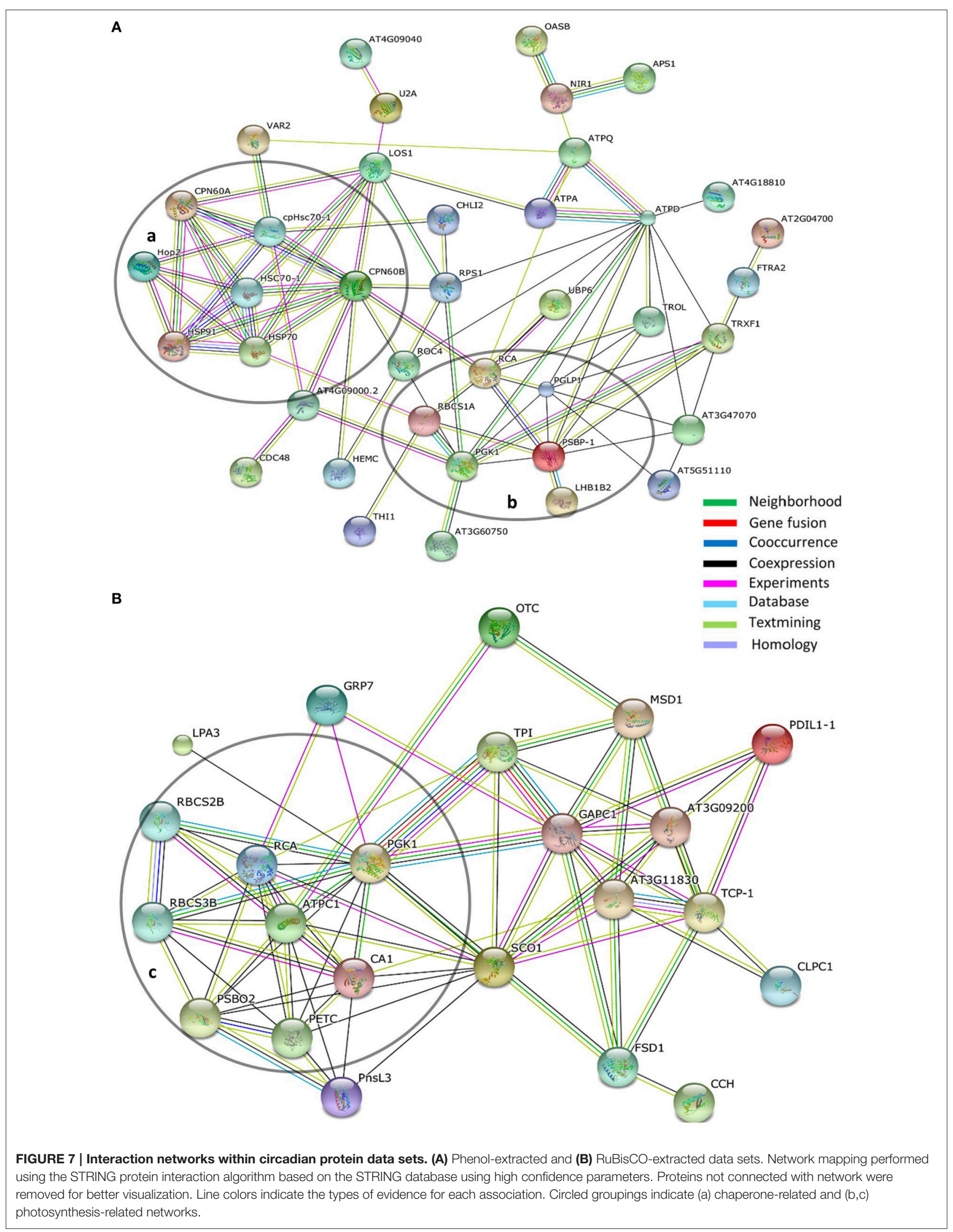


approach with an immuno-depletion technique in an effort to identify low abundance proteins that might be masked by the overwhelming presence of $\mathrm{RuBisCO}$. Among the proteins which cycled in abundance, 287 proteins were found overlapping between the two methods (Table S7) and only four emerged as similar top hits within their respective spots (Figure 4). These results indicate that the apparent discrepancies between the datasets do not come from two very different sets of results, but arise more from differences in the relative abundances among the many proteins recovered that are common to both extraction methods. From this perspective, the two extraction approaches were complementary and together enhanced our discovery of novel circadian-regulated proteins.

Two-dimensional electrophoresis (2-DE) does not have the resolution to separate all proteins into one single spot for each. Generally each spot contains more than one protein and the same protein may be detected from different spots due to post-translational modifications or proteolytic cleavage. The number of proteins detectable from any spot depends on the method used for identification, e.g., MALDI-TOF can detect fewer peptides than LC-MS/MS. In the present study we used an LTQ-Orbitrap XL, the most advanced MS technique, which enhanced detectability. Hence, more than one protein per spot is often detected (Thiede et al., 2013).

For each spot we selected the top hit or protein as the one having the most spectra, assuming that the top hit protein is the major contributor to spot pattern determination. It is practically not feasible to select a spot from each of the six analytical gels and analyze that same spot for each of the six time points. Hence, pooled samples were used for the preparative gels (see Section Methods). It is possible that the same non-cycling protein present at a given spot over the time series could obscure the oscillations of a less abundant protein, which will reduce recovery of low abundance, oscillating proteins. But this would likely show up as the top hit, but not be processed because we only analyzed spots showing oscillations. This same occurrence could also simply dampen the amplitude of a more dominant oscillating protein. Since all the time points were pooled for MS only proteins aberrantly very high at one or two time points could emerge as the top hit but not be the same protein responsible for the oscillating pattern. As well, multiple proteins with similar abundances within a spot could obscure or alter the waveform of an oscillating protein; in these cases interpretations must proceed with caution. In instances where the scores are very similar or identical we consider both the MW and PI for spot identity or if

\section{REFERENCES}

Akimoto, H., Wu, C., Kinumi, T., and Ohmiya, Y. (2004). Biological rhythmicity in expressed proteins of the marine dinoflagellate Lingulodinium polyedrum demonstrated by chronological proteomics. Biochem. Biophys. Res. Commun. 315, 306-312. doi: 10.1016/j.bbrc.2004. 01.054

Alban, A., David, S. O., Bjorkesten, L., Andersson, C., Sloge, E., Lewis, S., et al. (2003). A novel experimental design for comparative two-dimensional gel analysis: two-dimensional difference gel electrophoresis incorporating both parameters are similar we show both proteins as candidates (e.g., P77, S18; Tables S5, S6).

Often oscillations in protein levels reflect transcript rhythms, but with a phase delay of 2-3 h or more (Fujiwara et al., 2008; Nusinow et al., 2011; Rawat et al., 2011; Robles et al., 2014). Our results here, and previously (Choudhary et al., 2015), show that more than $35 \%$ of the rhythmic proteins lack a corresponding rhythmic transcript, in line with studies in other circadian systems (Reddy et al., 2006; Deery et al., 2009; Mauvoisin et al., 2014b; Robles et al., 2014). Clearly, a significant number of circadian-regulated proteins are being missed by a reliance on transcript oscillation as an indicator of polypeptide rhythms. Recent findings demonstrate that these rhythms may arise through circadian control of protein synthesis/translation (Künne et al., 1998; Jang et al., 2015; Janich et al., 2015; Missra et al., 2015; Feeney et al., 2016), protein turnover (Kim et al., 2003, 2007, 2011; van et al., 2011; Yoo et al., 2013; Stojkovic et al., 2014; DeBruyne et al., 2015), or a combination of the two. The circadian regulation of proteostasis appears underappreciated as a mechanism to control polypeptide levels. Our results will help initiate further investigations into the post-translational regulation of pathways and processes regulated by the Arabidopsis circadian system.

\section{AUTHOR CONTRIBUTIONS}

MC, HS, HN, and DS designed research; MC, YN, HS, and HN performed research; HN contributed new reagents or analytic tools; MC, HS, HN, and DS analyzed data; MC and DS wrote the paper.

\section{FUNDING}

This work was supported by National Institutes of Health Grant R01GM093285 (to DS) and the World Class University Program of South Korea (No. R31-2008-000-10105-0), NRF, MEST (to DS), and by JSPS KAKENHI Grant Numbers 26650106 and $15 \mathrm{H} 01247$ to $\mathrm{HN}$.

\section{SUPPLEMENTARY MATERIAL}

The Supplementary Material for this article can be found online at: http://journal.frontiersin.org/article/10.3389/fpls.2016. 01007 
Cardone, L., Hirayama, J., Giordano, F., Tamaru, T., Palvimo, J. J., and SassoneCorsi, P. (2005). Circadian clock control by SUMOylation of BMAL1. Science 309, 1390-1394. doi: 10.1126/science.1110689

Choudhary, M. K., Nomura, Y., Wang, L., Nakagami, H., and Somers, D. E. (2015). Quantitative circadian phosphoproteomic analysis of Arabidopsis reveals extensive clock control of key components in physiological, metabolic, and signaling pathways. Mol. Cell Proteomics 14, 2243-2260. doi: 10.1074/mcp.M114.047183

Covington, M. F., Maloof, J. N., Straume, M., Kay, S. A., and Harmer, S. L. (2008). Global transcriptome analysis reveals circadian regulation of key pathways in plant growth and development. Genome Biol. 9:R130. doi: 10.1186/gb-2008-98-r130

DeBruyne, J. P., Baggs, J. E., Sato, T. K., and Hogenesch, J. B. (2015). Ubiquitin ligase Siah2 regulates RevErbalpha degradation and the mammalian circadian clock. Proc. Natl. Acad. Sci. U.S.A. 112, 12420-12425. doi: 10.1073/pnas.1501204112

Deery, M. J., Maywood, E. S., Chesham, J. E., Sládek, M., Karp, N. A., Green, E. W., et al. (2009). Proteomic analysis reveals the role of synaptic vesicle cycling in sustaining the suprachiasmatic circadian clock. Curr. Biol. 19, 2031-2036. doi: 10.1016/j.cub.2009.10.024

Dodd, A. N., Salathia, N., Hall, A., Kévei, E., Tóth, R., Nagy, F., et al. (2005). Plant circadian clocks increase photosynthesis, growth, survival, and competitive advantage. Science 309, 630-633. doi: 10.1126/science.1115581

Feeney, K. A., Hansen, L. L., Putker, M., Olivares-Yañez, C., Day, J., Eades, L. J., et al. (2016). Daily magnesium fluxes regulate cellular timekeeping and energy balance. Nature 532, 375-379. doi: 10.1038/nature17407

Fellerer, C., Schweiger, R., Schöngruber, K., Soll, J., and Schwenkert, S. (2011). Cytosolic HSP90 cochaperones HOP and FKBP interact with freshly synthesized chloroplast preproteins of Arabidopsis. Mol. Plant 4, 1133-1145. doi: $10.1093 / \mathrm{mp} / \mathrm{ssr} 037$

Filichkin, S. A., Breton, G., Priest, H. D., Dharmawardhana, P., Jaiswal, P., Fox, S. E., et al. (2011). Global profiling of rice and poplar transcriptomes highlights key conserved circadian-controlled pathways and cis-regulatory modules. PLoS ONE 6:e16907. doi: 10.1371/journal.pone.0016907

Flores-Pérez, Ú., and Jarvis, P. (2013). Molecular chaperone involvement in chloroplast protein import. Biochim. Biophys. Acta 1833, 332-340. doi: 10.1016/j.bbamcr.2012.03.019

Fujiwara, S., Wang, L., Han, L., Suh, S. S., Salomé, P. A., McClung, C. R., et al. (2008). Post-translational regulation of the Arabidopsis circadian clock through selective proteolysis and phosphorylation of pseudo-response regulator proteins. J. Biol. Chem. 283, 23073-23083. doi: 10.1074/jbc.M803471200

Fukushima, A., Kusano, M., Nakamichi, N., Kobayashi, M., Hayashi, N., Sakakibara, H., et al. (2009). Impact of clock-associated Arabidopsis pseudoresponse regulators in metabolic coordination. Proc. Natl. Acad. Sci. U.S.A. 106, 7251-7256. doi: 10.1073/pnas.0900952106

Gendron, J. M., Pruneda-Paz, J. L., Doherty, C. J., Gross, A. M., Kang, S. E., and Kay, S. A. (2012). Arabidopsis circadian clock protein, TOC1, is a DNAbinding transcription factor. Proc. Natl. Acad. Sci. U.S.A. 109, 3167-3172. doi: 10.1073/pnas.1200355109

Graf, A., Schlereth, A., Stitt, M., and Smith, A. M. (2010). Circadian control of carbohydrate availability for growth in Arabidopsis plants at night. Proc. Natl. Acad. Sci. U.S.A. 107, 9458-9463. doi: 10.1073/pnas.0914299107

Green, R. M., Tingay, S., Wang, Z. Y., and Tobin, E. M. (2002). Circadian rhythms confer a higher level of fitness to Arabidopsis plants. Plant Physiol. 129, 576-584. doi: 10.1104/pp.004374

Greenham, K., and McClung, C. R. (2015). Integrating circadian dynamics with physiological processes in plants. Nat. Rev. Genet. 16, 598-610. doi: $10.1038 / \mathrm{nrg} 3976$

Harmer, S. L., Hogenesch, J. B., Straume, M., Chang, H. S., Han, B., Zhu, T., et al. (2000). Orchestrated transcription of key pathways in Arabidopsis by the circadian clock. Science 290, 2110-2113. doi: 10.1126/science.290.5499. 2110

Harmer, S. L., Panda, S., and Kay, S. A. (2001). Molecular bases of circadian rhythms. Annu. Rev. Cell Dev. Biol. 17, 215-253. doi: 10.1146/annurev.cellbio.17.1.215

Hazen, S. P., Naef, F., Quisel, T., Gendron, J. M., Chen, H., Ecker, J. R., et al. (2009). Exploring the transcriptional landscape of plant circadian rhythms using genome tiling arrays. Genome Biol. 10:R17. doi: 10.1186/gb-2009-10 2-r17

Heintzen, C., Nater, M., Apel, K., and Staiger, D. (1997). AtGRP7, a nuclear RNAbinding protein as a component of a circadian-regulated negative feedback loop in Arabidopsis thaliana. Proc. Natl. Acad. Sci. U.S.A. 94, 8515-8520. doi: 10.1073/pnas.94.16.8515

Herrero, J., Valencia, A., and Dopazo, J. (2001). A hierarchical unsupervised growing neural network for clustering gene expression patterns. Bioinformatics 17, 126-136. doi: 10.1093/bioinformatics/17.2.126

Hsu, P. Y., Devisetty, U. K., and Harmer, S. L. (2013). Accurate timekeeping is controlled by a cycling activator in Arabidopsis. Elife. 2:e00473. doi: 10.7554/eLife.00473

Huang, W., Pérez-García, P., Pokhilko, A., Millar, A. J., Antoshechkin, I., Riechmann, J. L., et al. (2012). Mapping the core of the Arabidopsis circadian clock defines the network structure of the oscillator. Science 336, 75-79. doi: $10.1126 /$ science. 1219075

Hurkman, W. J., and Tanaka, C. K. (1986). Solubilization of plant membrane proteins for analysis by two-dimensional gel electrophoresis. Plant Physiol. 81, 802-806. doi: 10.1104/pp.81.3.802

Hwang, H., Cho, M. H., Hahn, B. S., Lim, H., Kwon, Y. K., Hahn, T. R., et al. (2011). Proteomic identification of rhythmic proteins in rice seedlings. Biochim. Biophys. Acta 1814, 470-479. doi: 10.1016/j.bbapap.2011.01.010

Ishihama, Y., Rappsilber, J., Andersen, J. S., and Mann, M. (2002). Microcolumns with self-assembled particle frits for proteomics. J. Chromatogr. A 979, 233-239. doi: 10.1016/S0021-9673(02)01402-4

Jang, C., Lahens, N. F., Hogenesch, J. B., and Sehgal, A. (2015). Ribosome profiling reveals an important role for translational control in circadian gene expression. Genome Res. 25, 1836-1847. doi: 10.1101/gr.191296.115

Janich, P., Arpat, A. B., Castelo-Szekely, V., Lopes, M., and Gatfield, D. (2015). Ribosome profiling reveals the rhythmic liver translatome and circadian clock regulation by upstream open reading frames. Genome Res. 25, 1848-1859. doi: 10.1101/gr.195404.115

Jung, K. H., Gho, H. J., Nguyen, M. X., Kim, S. R., and An, G. (2013). Genomewide expression analysis of HSP70 family genes in rice and identification of a cytosolic HSP70 gene highly induced under heat stress. Funct. Integr. Genomics 13, 391-402. doi: 10.1007/s10142-013-0331-6

Keller, A., Nesvizhskii, A. I., Kolker, E., and Aebersold, R. (2002). Empirical statistical model to estimate the accuracy of peptide identifications made by MS/MS and database search. Anal. Chem. 74, 5383-5392. doi: $10.1021 / \mathrm{ac} 025747 \mathrm{~h}$

Kim, T. S., Kim, W. Y., Fujiwara, S., Kim, J., Cha, J. Y., Park, J. H., et al. (2011). HSP90 functions in the circadian clock through stabilization of the client Fbox protein ZEITLUPE. Proc. Natl. Acad. Sci. U.S.A. 108, 16843-16848. doi: 10.1073/pnas.1110406108

Kim, W. Y., Fujiwara, S., Suh, S. S., Kim, J., Kim, Y., Han, L., et al. (2007). ZEITLUPE is a circadian photoreceptor stabilized by GIGANTEA in blue light. Nature 449, 356-360. doi: 10.1038/nature06132

Kim, W. Y., Geng, R., and Somers, D. E. (2003). Circadian phase-specific degradation of the F-box protein ZTL is mediated by the proteasome. Proc. Natl. Acad. Sci. U.S.A. 100, 4933-4938. doi: 10.1073/pnas.0736949100

Künne, A., Pistorius, E., Kloppstech, K., and De Groot, E. J. (1998). Circadian synthesis of light-harvesting-chlorophyll-proteins in Euglena gracilis is under translational control. Z. Naturforsch. C. 53, 1017-1026.

Latijnhouwers, M., Xu, X. M., and Møller, S. G. (2010). Arabidopsis stromal 70$\mathrm{kDa}$ heat shock proteins are essential for chloroplast development. Planta 232, 567-578. doi: 10.1007/s00425-010-1192-Z

Le, B. T., Martin, S. F., Chirnside, E. S., van, O. G., Barrios-Llerena, M. E., O’Neill, J. S., et al. (2011). Shotgun proteomic analysis of the unicellular alga Ostreococcus tauri. J. Proteomics 74, 2060-2070. doi: 10.1016/j.jprot.2011.05.028

Lee, H. G., Mas, P., and Seo, P. J. (2016). MYB96 shapes the circadian gating of ABA signaling in Arabidopsis. Sci. Rep. 6:17754. doi: 10.1038/srep17754

Lee, K. H., Piao, H. L., Kim, H. Y., Choi, S. M., Jiang, F., Hartung, W., et al. (2006). Activation of glucosidase via stress-induced polymerization rapidly increases active pools of abscisic acid. Cell 126, 1109-1120. doi: 10.1016/j.cell.2006.07.034

Legnaioli, T., Cuevas, J., and Mas, P. (2009). TOC1 functions as a molecular switch connecting the circadian clock with plant responses to drought. EMBO J. 28, 3745-3757. doi: 10.1038/emboj.2009.297 
Lin, B. L., Wang, J. S., Liu, H. C., Chen, R. W., Meyer, Y., Barakat, A., et al. (2001). Genomic analysis of the Hsp70 superfamily in Arabidopsis thaliana. Cell Stress Chaperones 6, 201-208. doi: 10.1379/1466-1268(2001) $006<0201$ :GAOTHS $>2.0$.CO;2

Liu, T., Carlsson, J., Takeuchi, T., Newton, L., and Farré, E. M. (2013). Direct regulation of abiotic responses by the Arabidopsis circadian clock component PRR7. Plant J. 76, 101-114. doi: 10.1111/tpj.12276

Maiwald, D., Dietzmann, A., Jahns, P., Pesaresi, P., Joliot, P., Joliot, A., et al. (2003). Knock-out of the genes coding for the Rieske protein and the ATPsynthase delta-subunit of Arabidopsis. Effects on photosynthesis, thylakoid protein composition, and nuclear chloroplast gene expression. Plant Physiol. 133, 191-202. doi: 10.1104/pp.103.024190

Matsumoto, F., Obayashi, T., Sasaki-Sekimoto, Y., Ohta, H., Takamiya, K., and Masuda, T. (2004). Gene expression profiling of the tetrapyrrole metabolic pathway in Arabidopsis with a mini-array system. Plant Physiol. 135, 2379-2391. doi: 10.1104/pp.104.042408

Mauvoisin, D., Dayon, L., Gachon, F., and Kussmann, M. (2014a). Proteomics and circadian rhythms: It's all about signaling! Proteomics 15, 310-317. doi: 10.1002/pmic.201400187

Mauvoisin, D., Wang, J., Jouffe, C., Martin, E., Atger, F., Waridel, P., et al. (2014b). Circadian clock-dependent and -independent rhythmic proteomes implement distinct diurnal functions in mouse liver. Proc. Natl. Acad. Sci. U.S.A. 111, 167-172. doi: 10.1073/pnas.1314066111

Mehra, A., Baker, C. L., Loros, J. J., and Dunlap, J. C. (2009). Post-translational modifications in circadian rhythms. Trends Biochem. Sci. 34, 483-490. doi: 10.1016/j.tibs.2009.06.006

Millar, A. J., and Kay, S. A. (1991). Circadian control of cab gene transcription and mRNA accumulation in Arabidopsis. Plant Cell 3, 541-550. doi: 10.1105/tpc.3.5.541

Missra, A., Ernest, B., Lohoff, T., Jia, Q., Satterlee, J., Ke, K., et al. (2015). The circadian clock modulates global daily cycles of mRNA ribosome loading. Plant Cell 27, 2582-2599. doi: 10.1105/tpc.15.00546

Mizuno, T., and Yamashino, T. (2008). Comparative transcriptome of diurnally oscillating genes and hormone-responsive genes in Arabidopsis thaliana: insight into circadian clock-controlled daily responses to common ambient stresses in plants. Plant Cell Physiol. 49, 481-487. doi: 10.1093/pcp/pcn008

Mockler, T. C., Michael, T. P., Priest, H. D., Shen, R., Sullivan, C. M., Givan, S. A., et al. (2007). The DIURNAL project: DIURNAL and circadian expression profiling, model-based pattern matching, and promoter analysis. Cold Spring Harb. Symp. Quant. Biol. 72, 353-363. doi: 10.1101/sqb.2007.72.006

Morisse, S., Michelet, L., Bedhomme, M., Marchand, C. H., Calvaresi, M., Trost, P., et al. (2014). Thioredoxin-dependent redox regulation of chloroplastic phosphoglycerate kinase from Chlamydomonas reinhardtii. J. Biol. Chem. 289, 30012-30024. doi: 10.1074/jbc.M114.597997

Nagel, D. H., Doherty, C. J., Pruneda-Paz, J. L., Schmitz, R. J., Ecker, J. R., and Kay, S. A. (2015). Genome-wide identification of CCA1 targets uncovers an expanded clock network in Arabidopsis. Proc. Natl. Acad. Sci. U.S.A. 112, E4802-E4810. doi: 10.1073/pnas.1513609112

Nakamichi, N., Kiba, T., Kamioka, M., Suzuki, T., Yamashino, T., Higashiyama, T., et al. (2012). Transcriptional repressor PRR5 directly regulates clockoutput pathways. Proc. Natl. Acad. Sci. U.S.A. 109, 17123-17128. doi: 10.1073/pnas.1205156109

Nesvizhskii, A. I., Keller, A., Kolker, E., and Aebersold, R. (2003). A statistical model for identifying proteins by tandem mass spectrometry. Anal. Chem. 75, 4646-4658. doi: 10.1021/ac0341261

Nolte, C., and Staiger, D. (2015). RNA around the clock - regulation at the RNA level in biological timing. Front. Plant Sci. 6:311. doi: 10.3389/fpls.2015. 00311

Noordally, Z. B., Ishii, K., Atkins, K. A., Wetherill, S. J., Kusakina, J., Walton, E. J., et al. (2013). Circadian control of chloroplast transcription by a nuclearencoded timing signal. Science 339, 1316-1319. doi: 10.1126/science.1230397

Nose, M., and Watanabe, A. (2014). Clock genes and diurnal transcriptome dynamics in summer and winter in the gymnosperm Japanese cedar (Cryptomeria japonica L.f. D. Don). BMC. Plant Biol. 14:308. doi: 10.1186/s12870-014-0308-1

Nováková, M., Motyka, V., Dobrev, P. I., Malbeck, J., Gaudinová, A., and Vanková, R. (2005). Diurnal variation of cytokinin, auxin and abscisic acid levels in tobacco leaves. J. Exp. Bot. 56, 2877-2883. doi: 10.1093/jxb/eri282
Nusinow, D. A., Helfer, A., Hamilton, E. E., King, J. J., Imaizumi, T., Schultz, T. F., et al. (2011). The ELF4-ELF3-LUX complex links the circadian clock to diurnal control of hypocotyl growth. Nature 475, 398-402. doi: 10.1038/nature10182

van, O. G., Dixon, L. E., Troein, C., and Millar, A. J. (2011). Proteasome function is required for biological timing throughout the twenty-four hour cycle. Curr. Biol. 21, 869-875. doi: 10.1016/j.cub.2011.03.060

Olsen, J. V., de Godoy, L. M., Li, G., Macek, B., Mortensen, P., Pesch, R., et al. (2005). Parts per million mass accuracy on an Orbitrap mass spectrometer via lock mass injection into a C-trap. Mol. Cell Proteomics 4, 2010-2021. doi: 10.1074/mcp.T500030-MCP200

Olsen, J. V., Ong, S. E., and Mann, M. (2004). Trypsin cleaves exclusively Cterminal to arginine and lysine residues. Mol. Cell Proteomics 3, 608-614. doi: 10.1074/mcp.T400003-MCP200

Pokhilko, A., Mas, P., and Millar, A. J. (2013). Modelling the widespread effects of TOC1 signalling on the plant circadian clock and its outputs. BMC. Syst. Biol. 7:23. doi: 10.1186/1752-0509-7-23

Radons, J. (2016). The human HSP70 family of chaperones: where do we stand? Cell Stress Chaperones 21, 379-404. doi: 10.1021/ac026117i

Rappsilber, J., Ishihama, Y., and Mann, M. (2003). Stop and go extraction tips for matrix-assisted laser desorption/ionization, nanoelectrospray, and LC/MS sample pretreatment in proteomics. Anal. Chem. 75, 663-670. doi: 10.1021/ac026117i

Ravichandran, A., Sugiyama, N., Tomita, M., Swarup, S., and Ishihama, Y. (2009). Ser/Thr/Tyr phosphoproteome analysis of pathogenic and non-pathogenic Pseudomonas species. Proteomics 9, 2764-2775. doi: 10.1002/pmic.200800655

Rawat, R., Takahashi, N., Hsu, P. Y., Jones, M. A., Schwartz, J., Salemi, M. R., et al. (2011). REVEILLE8 and PSEUDO-REPONSE REGULATOR5 form a negative feedback loop within the Arabidopsis circadian clock. PLoS Genet. 7:e1001350. doi: 10.1371/journal.pgen.1001350

Reddy, A. B., Karp, N. A., Maywood, E. S., Sage, E. A., Deery, M., O’Neill, J. S., et al. (2006). Circadian orchestration of the hepatic proteome. Curr. Biol. 16, 1107-1115. doi: 10.1016/j.cub.2006.04.026

Robles, M. S., Cox, J., and Mann, M. (2014). In-vivo quantitative proteomics reveals a key contribution of post-transcriptional mechanisms to the circadian regulation of liver metabolism. PLoS Genet. 10:e1004047. doi: 10.1371/journal.pgen.1004047

Romijn, E. P., Christis, C., Wieffer, M., Gouw, J. W., Fullaondo, A., van der Sluijs, P., et al. (2005). Expression clustering reveals detailed co-expression patterns of functionally related proteins during B cell differentiation: a proteomic study using a combination of one-dimensional gel electrophoresis, LC-MS/MS, and stable isotope labeling by amino acids in cell culture (SILAC). Mol. Cell Proteomics 4, 1297-1310. doi: 10.1074/mcp.M500123-MCP200

Saeed, A. I., Sharov, V., White, J., Li, J., Liang, W., Bhagabati, N., et al. (2003). TM4: a free, open-source system for microarray data management and analysis. BioTechniques 34, 374-378.

Schmal, C., Reimann, P., and Staiger, D. (2013). A circadian clock-regulated toggle switch explains AtGRP7 and AtGRP8 oscillations in Arabidopsis thaliana. PLoS Comput. Biol. 9:e1002986. doi: 10.1371/journal.pcbi.1002986

Sehrawat, A., Abat, J. K., and Deswal, R. (2013). RuBisCO depletion improved proteome coverage of cold responsive S-nitrosylated targets in Brassica juncea. Front. Plant Sci. 4:342. doi: 10.3389/fpls.2013.00342

Seo, P. J., and Mas, P. (2014). Multiple layers of posttranslational regulation refine circadian clock activity in Arabidopsis. Plant Cell. 26, 79-87. doi: 10.1105/tpc.113.119842

Seung, D., Risopatron, J. P., Jones, B. J., and Marc, J. (2012). Circadian clockdependent gating in ABA signalling networks. Protoplasma 249, 445-457. doi: 10.1007/s00709-011-0304-3

Shevchenko, A., Tomas, H., Havlis, J., Olsen, J. V., and Mann, M. (2006). In-gel digestion for mass spectrometric characterization of proteins and proteomes. Nat. Protoc. 1, 2856-2860. doi: 10.1038/nprot.2006.468

Stojkovic, K., Wing, S. S., and Cermakian, N. (2014). A central role for ubiquitination within a circadian clock protein modification code. Front. Mol. Neurosci. 7:69. doi: 10.3389/fnmol.2014.00069

$\mathrm{Su}$, P. H., and Li, H. M. (2010). Stromal Hsp70 is important for protein translocation into pea and Arabidopsis chloroplasts. Plant Cell 22, 1516-1531. doi: $10.1105 /$ tpc. 109.071415

Sung, D. Y., and Guy, C. L. (2003). Physiological and molecular assessment of altered expression of Hsc70-1 in Arabidopsis. Evidence for pleiotropic 
consequences. Plant Physiol 132, 979-987. doi: 10.1104/pp.102. 019398

Szklarczyk, D., Franceschini, A., Wyder, S., Forslund, K., Heller, D., HuertaCepas, J., et al. (2015). STRING v10: protein-protein interaction networks, integrated over the tree of life. Nucleic Acids Res. 43, D447-D452. doi: 10.1093/nar/gku1003

Thiede, B., Koehler, C. J., Strozynski, M., Treumann, A., Stein, R., Zimny-Arndt, U., et al. (2013). High resolution quantitative proteomics of HeLa cells protein species using stable isotope labeling with amino acids in cell culture(SILAC), two-dimensional gel electrophoresis(2DE) and nano-liquid chromatograpohy coupled to an LTQ-OrbitrapMass spectrometer. Mol. Cell Proteomics 12, 529-538. doi: 10.1074/mcp.M112.019372

Trösch, R., Mühlhaus, T., Schroda, M., and Willmund, F. (2015). ATP-dependent molecular chaperones in plastids-more complex than expected. Biochim. Biophys. Acta 1847, 872-888. doi: 10.1016/j.bbabio.2015.01.002

van Wijk, K. J., Friso, G., Walther, D., and Schulze, W. X. (2014). Meta-analysis of Arabidopsis thaliana phospho-proteomics data reveals compartmentalization of phosphorylation motifs. Plant Cell 26, 2367-2389. doi: $10.1105 /$ tpc. 114.125815

Vizcaíno, J. A., Csordas, A., del-Toro, N., Dianes, J. A., Griss, J., Lavidas, I., et al. (2016). 2016 update of the PRIDE database and its related tools. Nucleic Acids Res. 44, D447-D456. doi: 10.1093/nar/gkv1145

Wagner, V., Fiedler, M., Markert, C., Hippler, M., and Mittag, M. (2004). Functional proteomics of circadian expressed proteins from Chlamydomonas reinhardtii. FEBS Lett. 559, 129-135. doi: 10.1016/S0014-5793(04)00051-1

Wagner, V., and Mittag, M. (2009). Probing circadian rhythms in Chlamydomonas rheinhardtii by functional proteomics. Methods Mol. Biol. 479, 173-188. doi: 10.1007/978-1-59745-289-2_11

Wu, G., Ortiz-Flores, G., Ortiz-Lopez, A., and Ort, D. R. (2007). A point mutation in atpC1 raises the redox potential of the Arabidopsis chloroplast ATP synthase gamma-subunit regulatory disulfide above the range of thioredoxin modulation. J. Biol. Chem. 282, 36782-36789. doi: 10.1074/jbc.M7070 07200
Yin, Z., Meng, F., Song, H., Wang, X., Xu, X., and Yu, D. (2010). Expression quantitative trait loci analysis of two genes encoding RuBisCO activase in soybean. Plant Physiol. 152, 1625-1637. doi: 10.1104/pp.109.148312

Yoo, S. H., Mohawk, J. A., Siepka, S. M., Shan, Y., Huh, S. K., Hong, H. K., et al. (2013). Competing E3 ubiquitin ligases govern circadian periodicity by degradation of CRY in nucleus and cytoplasm. Cell 152, 1091-1105. doi: 10.1016/j.cell.2013.01.055

Yoon, M., Putterill, J. J., Ross, G. S., and Laing, W. A. (2001). Determination of the relative expression levels of RuBisCO small subunit genes in Arabidopsis by rapid amplification of cDNA ends. Anal. Biochem. 291, 237-244. doi: 10.1006/abio.2001.5042

Yoshida, T., Mogami, J., and Yamaguchi-Shinozaki, K. (2015). Omics approaches toward defining the comprehensive abscisic acid signaling network in plants. Plant Cell Physiol. 56, 1043-1052. doi: 10.1093/pcp/pcv060

Zhang, Z., Quick, M. K., Kanelakis, K. C., Gijzen, M., and Krishna, P. (2003). Characterization of a plant homolog of hop, a cochaperone of hsp90. Plant Physiol. 131, 525-535. doi: 10.1104/pp.011940

Zulawski, M., Braginets, R., and Schulze, W. X. (2013). PhosPhAt goes kinases - searchable protein kinase target information in the plant phosphorylation site database PhosPhAt. Nucleic Acids Res. 41, D1176-D1184. doi: $10.1093 /$ nar/gks1081

Conflict of Interest Statement: The authors declare that the research was conducted in the absence of any commercial or financial relationships that could be construed as a potential conflict of interest.

Copyright (c) 2016 Choudhary, Nomura, Shi, Nakagami and Somers. This is an open-access article distributed under the terms of the Creative Commons Attribution License (CC BY). The use, distribution or reproduction in other forums is permitted, provided the original author(s) or licensor are credited and that the original publication in this journal is cited, in accordance with accepted academic practice. No use, distribution or reproduction is permitted which does not comply with these terms. 